\title{
Influência da assistência à saúde ofertada ao paciente surdo: uma revisão de literatura
}

\author{
Influence of health care offered to deaf patients: a literature review
}

Influencia de la asistencia sanitaria ofrecida a los pacientes sordos: una revisión de la literatura

Eclair Graciano Inácio ${ }^{1 *}$, Luís Fernando Borja Gómez¹, Ynez Lopez de Souza Cruz¹, Natanael da Silva Nascimento1, Lucas Oliveira Ribeiro¹, João Gabriel Gomes Queiroz¹, Octávio Augusto Cavalcante Fortes ${ }^{1}$, Romão de Carvalho Ferreira ${ }^{1}$, Gustavo Henrique Sinhorin ${ }^{1}$.

\section{RESUMO}

Objetivos: Analisar e avaliar o impacto da assistência à saúde ofertada ao paciente surdo. Métodos: Tratase de uma revisão integrativa de literatura, cujo levantamento de informações foi realizado em banco de dados eletrônicos: Literatura Latino-Americana e do Caribe em Ciências da Saúde (LILACS), Medical Literature Analysis and Retrieval System Online (MEDLINE), Scientific Eletronic Library Online (SciELO) e PubMed. Em relação a critério de inclusão, foram selecionados os artigos dos últimos 10 anos. Em relação a critério de exclusão, foram desconsiderados artigos que não abordaram o tema proposto. Resultados: Essa revisão literária está composta por 11 artigos que trazem informações referente sobre profissional de saúde e paciente, com percepções do atendimento de ambos os lados. Considerações finais: Sugere-se que os surdos possuem maior tendência a adoecer com maior facilidade em relação à população ouvinte. Outro fator que corrobora é a comunicação prejudicada entre paciente e médico, que reduz entendimento sobre prevenção, diagnóstico e tratamento.

Palavras-chave: Surdo, Percepção, Saúde, Doenças, Atendimento.

\begin{abstract}
Objectives: To analyze and evaluate the impact of health care offered to deaf patients. Methods: This is an integrative literature review, whose information was collected in an electronic database: Latin American Literature and the Caribbean in Health Sciences (LILACS), Medical Literature Analysis and Retrieval System Online (MEDLINE), Scientific Electronic Library Online (SciELO) and PubMed. Regarding the inclusion criteria, articles from the last 10 years were selected. Regarding the exclusion criteria, articles that did not address the proposed theme were disregarded. Results: This literary review is composed of 11 articles that provide information regarding health professionals and patients, with perceptions of care from both sides. Final considerations: It is suggested that the deaf have a greater tendency to get sick more easily compared to the hearing population. Another factor that corroborates is the impaired communication between patient and physician, which reduces understanding about prevention, diagnosis and treatment.
\end{abstract}

Keywords: Deaf, Perception, Health, Ilnesses, Attendance.

\section{RESUMEN}

Objetivos: Analizar y evaluar el impacto de la atención sanitaria ofrecida a los pacientes sordos. Métodos: Esta es una revisión integradora de la literatura, cuya información fue recogida en una base de datos electrónica: Literatura Latinoamericana y la Caribbean in Health Sciences (LILACS), Sistema de análisis y recuperación de literatura médica en línea (MEDLINE), Scientific Biblioteca Electrónica en Línea

${ }^{1}$ Universidade Federal do Acre (UFAC), Rio Branco - AC. *E-mail: eclair.ufac@outlook.com

SUBMETIDO EM: 10/2021

ACEITO EM: 10/2021

PUBLICADO EM: 11/2021 
(SciELO) y PubMed. En cuanto a los criterios de inclusión, la artículos de los últimos 10 años. En cuanto a los criterios de exclusión, se descartaron los artículos que no abordaban el tema. propuesto. Resultados: Esta revisión de literatura está compuesta por 11 artículos que traen información sobre la relación entre profesionales de la salud y pacientes, con percepciones del cuidado de ambos lados. Consideraciones finales: Se sugiere que los sordos tienen una mayor tendencia a enfermarse más fácilmente en comparación con la población oyente. Otro factor que lo corrobora es la alteración de la comunicación entre paciente y médico, lo que reduce la comprensión sobre prevención, diagnóstico y tratamiento.

Palabras clave: Sordos, Percepción, Salud, Enfermedades, Asistencia.

\section{INTRODUÇÃO}

Em cada época da história, os surdos receberam diferentes tratamentos de acordo com um conjunto de fatores que moldavam ações e pensamentos no período histórico que a sociedade estava inserida. Os registros mais antigos que se tem conhecimento são da Grécia Antiga. A razão e a filosofia dominavam o modo de pensar dessa época. Aristóteles, filósofo de 355 a.C., afirmava que surdos e natissurdos se tornam desprovidos de razão e incapazes de racionalizar pela falta da audição. Galeno, médico grego, afirmava que audição e fala vinham da mesma origem do cérebro, então se houver defeito na audição, a fala também será afetada. Essas duas ideias foram aceitas como verdadeiras até o século XVI (WITKOSKY AS, 2015; STROBEL K, 2009; DUARTE SBR, et al., 2013).

Como frisado, o século XVI foi marcado por uma diferente perspectiva para os surdos, que de certo modo os beneficiaram e abriram oportunidades inimagináveis em épocas passadas. Outro ponto importante e que merece realce é o fato de que considerável parcela de famílias nobres detentoras de posses tinha surdos como herdeiros primogênitos, haja vista que era comum casamentos consanguíneos, e essa condição de não ouvirem, retiravam a possiblidade de receberem os títulos e bens materiais, devido às ideias concebidas na Grécia Antiga e que se faziam presentes e eram vistas como verdadeiras. Então para não haver esse risco, traçaram um novo modo de enxergar e novos esforços foram feitos para educar os surdos (SACKS O, 2010).

Os avanços e mudanças começaram a ganhar recrudescimento no século XVIII, através de dois métodos de ensino: o método oralista ensinado por Samuel Heinicke e o método de gramática francesa associado com gestos de mãos ensinado pelo abade Charles Michel de l'Épeé. Até o século XIX, o método gestual ganhou espaço em seu país de origem, França, que posteriormente ganhou novos centros de ensino pela Europa e América. Mas em 1880, houve o Congresso de Milão, onde foi votado qual método seria ensinado pelo mundo. Com a maioria dos participantes sendo ouvintes e voltados para os ensinamentos de Samuel Heinicke, foi escolhido o método oralista. Não houve participação de indivíduos surdos na votação. Então, todos os centros de ensino criados para o ensino do método de l'Épeé tiveram suas atividades encerradas (DUARTE SBR, et al., 2013; WITKOSKY AS, 2015).

Todo esse novo cenário perdurou até década de 1970, momento em que o movimento nomeado de Comunicação Total ganhou corpo e repercussão em várias partes do mundo. A filosofia do movimento é garantir a interação de pessoas, não só entre surdos, mas também entre surdos e ouvintes. A ideia era desenvolver diferentes capacidades para a comunicação, de modo a estimular a cognição, socioemocional e aprendizagem (FERNANDES S, 2011; DUARTE SBR, et al., 2013).

Inicia-se no Brasil Imperial de Dom Pedro II, através de um convite, em 1855, do imperador brasileiro para Hernest Huet, ex-aluno de l'Épeé, com a finalidade de fundar uma unidade de ensino aos surdos. Em 1857, foi criado o Imperial Instituto dos Surdos-Mudos, cujo nome, em 1958, foi alterado para Instituto Nacional de Educação de Surdos (INES). Frisando que a instituição aceitava apenas alunos surdos do sexo masculino com idade entre 7 a 14 anos. O resultado do Congresso de Milão, em 1880, surtiu mudanças no ensino ofertado pela instituição, com o impedimento de lecionar o método gestual e de estabelecer comunicação pela linguagem gestual. Apenas na década de 1970, houve mudanças que possibilitaram a língua de sinais ganhar espaço novamente para ser lecionada. Conquista alcançada através do movimento Comunicação Total, que também teve suas ideias ecoando no cenário brasileiro (WITKOSKY AS, 2015; DUARTE SBR, et al., 2013). 
A surdez em termos orgânicos é definida como o indivíduo que apresenta déficit auditivo e pode haver variações quanto a acuidade auditiva. Mas o fato é que considerar surdez apenas como deficiência sensorial, está relacionado com uma visão oralista onde se observa apenas aspectos biológicos do indivíduo surdo. Então surdez deve ser entendida como um modo diferente de interagir com o mundo e não como uma deficiência somente (NOBREGA JD, et al., 2012).

O surdo não pode ser visto como deficiente, ou inferior a nenhum ouvinte. O indivíduo não-ouvinte tem total capacidade de aprendizagem, com a diferença de que a construção cognitiva, socioemocional, sociocultural, linguagem, costumes será influenciado, majoritariamente, por experiência visual. Nesse âmbito, a cultura surda faz também parte da definição. A acuidade que a visão teve suplantou a ausência auditiva. Mas não só utilizada para perceber o que se passa no ambiente, visto todas as sutilezas em uma relação social também serão percebidas. Para os surdos a Língua de Sinais (LS) é vista como natural e associado com a visão, constrói-se um conjunto de comportamentos, que possuem regras, valores e tradições próprias (STROBEL K, 2016; DUARTE SBR, et al., 2013; FARIAS M e CUNHA B, 2017).

Através da história, pôde-se perceber que os direitos dos surdos sofreram alterações ao longo do tempo, de modo que houve épocas em se assegurava aos não-ouvintes a possibilidade de exercer a cidadania, contrastando com outras épocas em que perdiam todas as garantias que permitiam existir com a dignidade que todo ser humano tem direito (DUARTE SBR, et al., 2013).

Em 24 de abril de 2002, com a Lei Federal 10.436, a Língua Brasileira de Sinais (LIBRAS) foi oficialmente reconhecida como a segunda língua oficial do Brasil. O Art. $3^{\circ}$ dessa Lei aponta que em locais de serviços de saúde para atendimento ao público, seja apoiado e usado o uso de Libras para assegurar melhor atendimento e tratamento aos pacientes surdos. Posteriormente, seguiu-se com novas homologações referentes a outros âmbitos, como os referentes para recursos visuais em veiculação de propagandas e anúncios nacionais. Em relação à saúde, em 2005, o Decreto 5.626 regulamentou as seguintes Leis anteriormente aplicadas: Lei $n^{\circ} 10.436 / 2002$ e o Art. $18^{\circ}$ da Lei 10.098/2000. Esse decreto, dentre os direitos assegurados, que o paciente surdo seja assistido por profissionais capacitados em Libras com a finalidade de garantir o melhor atendimento às pessoas surdas (BRASIL, 2002; BRASIL, 2005).

Outro dado que reforça a necessidade de uma assistência adequada aos não-ouvintes está explicitado na

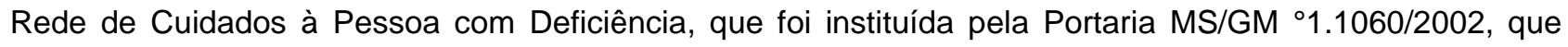
aponta o dever em disponibilizar comunicação adequada aos surdos para o processo de inclusão aos serviços oferecidos na área da sáude. Mas o que se observa nos locais de atendimento à saúde, desde o Atendmento Primário à Saúde até demais níveis mais complexos é o fato de que uma pequena minoria de profissionais consegue se comunicar em Libras (MELO CS, et al., 2021).

Dados da Pesquisa Nacional de Saúde/Instituto Brasileiro de Geografia e Estatística (IBGE) de 2013, aponta que $1,1 \%$, da população brasileira possuíam deficiência auditiva, sendo que, do total populacional, $0,2 \%$, em torno de 400.000 pessoas, são natissurdos. Em cerca de $91 \%$ dos lares que há um indivíduo surdo, os familiares apresentam dificuldades de comunicação por inexperiência ao lidar com surdez (IBGE, 2013; CHAVEIRO N, et al., 2014).

Os surdos tendem a não procurar assistência médica com menos frequência que os ouvintes, mesmo quando o atendimento à saúde do indivíduo se torna imprescindível para a resolução de um quadro clínico que necessite ser avaliado e conduzido. São pacientes que possuem receio em serem atendidos, devido a não serem respeitados e entendidos, pois a comunicação para essa população ocorre através da linguagem de sinal. Medo, desconfiança e frustração desencorajam os não-ouvintes em buscar ajuda médica. Os próprios profissionais de saúde não possuem preparo para receberem pacientes surdos, o que deixa, por muitas vezes, um atendimento desumanizado e não sensibilizado para acolhimento (BARNETT S, et al., 2011; SOUZA MFNS, et al., 2017).

Estando ciente que uma relação saudável médico-paciente é essencial para um resultado positivo no serviço prestado, o presente artigo teve como objetivo analisar o impacto que a influência da assistência à saúde ofertada ao paciente surdo. 


\section{MÉTODOS}

Trata-se de uma revisão integrativa de literatura de abordagem qualitativa, sendo os artigos consultados em banco de dados digitais: Literatura Latino-Americana e do Caribe em Ciências da Saúde (LILACS), Medical Literature Analysis and Retrieval System Online (MEDLINE), Scientific Eletronic Library Online (SciELO), Biblioteca Virtual em Saúde (BVS) e PubMed. Os descritores utilizados na pesquisa foram surdo, percepção saúde, doenças, atendimento. Suas variações em inglês e espanhol também foram utilizadas.

Foram excluídos os artigos que se distanciavam do tema proposto, Trabalho de Conclusão de Curso (TCC), relato de caso, monografias, trabalhos incompletos. Em relação aos critérios de inclusão, foram considerados os artigos dos últimos 7 anos de publicação, que compreende o período de 2015 a 2021, que fossem gratuitas e que também estivessem nos idiomas inglês e espanhol.Os artigos foram pesquisados no período de junho de 2019 a janeiro de 2020. Foram achados 80 artigos que abordavam o tema. Após análise dos artigos verificou-se que 37 se encaixavam na proposta dessa estudos. 24 artigos foram descartados, devido período de publicação ultrapassar 7 anos.

A Figura 1 representa esquematicamente o fluxograma para seleção dos artigos para o proposto estudo. Inicialmente, o tema foi escolhido por interesse e afinidade como assunto. Em seguida, traçou-se os objetivos que seriam realizados com o estudo. A busca dos referentes artigos foi realizada nas bases de dados eletrônicos, parágrafos anteriores já explicitados, onde foi achados 80 estudos que abordavam o tema escolhido. Com a primeira seleção foram excluídos 43 artigos, pois apresentavam critérios de exclusão já definidos em parágrafos anteriores. A segunda seleção ocorreu para verificação da data de publicação, haja vista que foram considerados os artigos dos últimos 7 anos de publicação e, com isso, foram exluídos 26 artigos da primeira seleção. Permaneceram 11 artigos remanescentes, que se enquadram adequadamente nos critérios de inclusão.

Figura 1 - Fluxograma para seleção de artigos, de acordo com critérios de inclusão e exclusão.

\begin{tabular}{|c|c|c|c|}
\hline $\begin{array}{c}\text { Estudos buscados } \\
\text { em bases de } \\
\text { dados eletrônicos. } \\
\left.\text { [N }{ }^{\circ} \mathbf{8 0}\right]\end{array}$ & $\begin{array}{c}\text { Estudos } \\
\text { selecionados. } \\
\text { Primeira } \\
\text { seleção [N³7] }\end{array}$ & $\begin{array}{c}\text { Estudos } \\
\text { selecionados. } \\
\text { Segunda seleção } \\
{\left[\mathrm{N}^{\circ} 11\right]}\end{array}$ & $\begin{array}{c}11 \text { artigos } \\
\text { selecionados de } \\
\text { acordo com } \\
\text { critérios anteriores }\end{array}$ \\
\hline
\end{tabular}

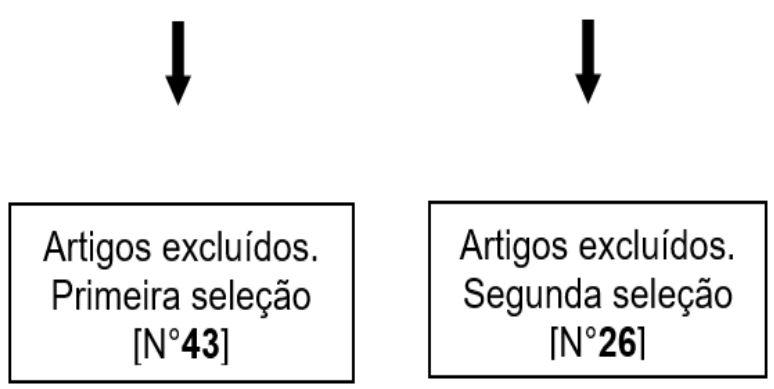

Fonte: Inácio EG, et al., 2021.

\section{RESULTADOS E DISCUSSÃO}

O Quadro 1 apresenta os 11 artigos selecionados a partir dos 80 artigos inicialmente achados. As informações priorizadas para serem inseridas ao quadro foram escolhidas de tal modo que é possível identificar a revista de divulgação, os autores, o ano de publicação, os objetivos e as respectivas conclusões de cada estudo. Desse modo, as informações essenciais referentes a cada um dos artigos ficam com melhor acessibilidade para serem buscadas. Os artigos foram colocados em ordem cronológica. 
Quadro 1 - Relação dos resultados selecionados e síntese das principais informações.

\begin{tabular}{|c|c|c|c|c|}
\hline Revista & Autores (ano) & Título & Objetivos & Conclusões \\
\hline $\begin{array}{l}\text { Revista Saúde } \\
\text { (Santa Maria) }\end{array}$ & $\begin{array}{l}\text { NASCIMENTO GB, } \\
\text { et al. (2015). }\end{array}$ & $\begin{array}{l}\text { Estratégias de comunicação } \\
\text { como dispositivo para o } \\
\text { atendimento humanizado em } \\
\text { saúde da pessoa surda. }\end{array}$ & $\begin{array}{l}\text { Investigar a percepção de surdos } \\
\text { sobre estratégias de comunicação } \\
\text { estabelecidas com profissionais } \\
\text { de saúde durante o atendimento. }\end{array}$ & $\begin{array}{l}\text { Há falta de intermediação na consulta na maioria das consultas. } \\
\text { Profissionais usam expressões inadequadas durante } \\
\text { comunicação. Paciente perde sua autonomia sem um } \\
\text { acolhimento correto }\end{array}$ \\
\hline BMJ Open & $\begin{array}{l}\text { EMOND A, et al. } \\
\qquad(2015)\end{array}$ & $\begin{array}{l}\text { The current health of the } \\
\text { signing Deaf community in the } \\
\text { UK compared with the general } \\
\text { population: a cross-sectional } \\
\text { study. }\end{array}$ & $\begin{array}{l}\text { Avaliar a saúde atual da } \\
\text { comunidade surda no Reino Unido } \\
\text { e comparar com a população em } \\
\text { geral. }\end{array}$ & $\begin{array}{l}\text { A saúde das pessoas surdas é pior do que a da população em } \\
\text { geral, com provável subdiagnóstico e subtratamento de } \\
\text { condições crônicas, colocando-as em risco de doenças } \\
\text { evitáveis. }\end{array}$ \\
\hline $\begin{array}{l}\text { Infarma - Ciências } \\
\text { Farmacêuticas }\end{array}$ & $\begin{array}{l}\text { NEVES DB, et al. } \\
\text { (2016). }\end{array}$ & $\begin{array}{l}\text { Atendimento aos surdos nos } \\
\text { serviços de saúde: } \\
\text { acessibilidade e obstáculos. }\end{array}$ & $\begin{array}{l}\text { Compreender a acessibilidade aos } \\
\text { serviços de saúde entre pessoas } \\
\text { surdas, diagnosticando problemas } \\
\text { e obstáculos que enfrentam. }\end{array}$ & $\begin{array}{l}\text { Dificuldade em receberem informações adequadas para } \\
\text { procedimentos e tratamentos. Comunicação fica prejudicada } \\
\text { sem intermediação e/ou profissionais capacitados. Pacientes } \\
\text { sentem-se discriminados, isolados e desrespeitados, mas } \\
\text { desejam entender melhor sobre a sua saúde e querem mais } \\
\text { autonomia. }\end{array}$ \\
\hline $\begin{array}{l}\text { Journal of Research } \\
\text { Fundamental Care } \\
\text { Online }\end{array}$ & $\begin{array}{l}\text { ARAGÃO JS, et al. } \\
(2017) .\end{array}$ & $\begin{array}{l}\text { Access and ommunication of } \\
\text { deaf adults: a voice silenced in } \\
\text { health services. }\end{array}$ & $\begin{array}{l}\text { Investigar o acesso e a } \\
\text { comunicação de adultos surdos } \\
\text { nos serviços de saúde. }\end{array}$ & $\begin{array}{l}\text { O acesso dos surdos nos serviços de saúde é permeado por } \\
\text { dificuldades, sendo a dificuldade da comunicação não verbal } \\
\text { um dos principais fatores que fragiliza a inclusão desses } \\
\text { sujeitos. }\end{array}$ \\
\hline $\begin{array}{c}\text { Revista } \\
\text { Enfermagem Atual }\end{array}$ & $\begin{array}{l}\text { CAVAGNA VM, et } \\
\text { al. (2017). }\end{array}$ & $\begin{array}{l}\text { O paciente surdo e suas } \\
\text { vivências no sistema de saúde: } \\
\text { uma interface da enfermagem. }\end{array}$ & $\begin{array}{l}\text { Identificar como se dá o } \\
\text { atendimento ao paciente surdo e } \\
\text { analisar as barreiras de } \\
\text { comunicação do profissional de } \\
\text { saúde nestes atendimentos. }\end{array}$ & $\begin{array}{l}\text { Há necessidade por capacitação dos profissionais de saúde } \\
\text { para melhorar a relação ao processo de comunicação. }\end{array}$ \\
\hline Revista CEFAC & $\begin{array}{l}\text { SOUZA MFNS } \\
\text { (2017). }\end{array}$ & $\begin{array}{l}\text { Principais dificuldades e } \\
\text { obstáculos enfrentados pela } \\
\text { comunidade surda no acesso à } \\
\text { saúde: uma revisão integrativa } \\
\text { de literatura. }\end{array}$ & $\begin{array}{l}\text { Identificar na literatura } r \\
\text { principais os } \\
\text { dificuldades enstáculos } \\
\text { pessoas surdas quanto ao acesso } \\
\text { à saúde. }\end{array}$ & $\begin{array}{l}\text { Comunicação deficitária impede que haja atendimento eficiente. } \\
\text { A falta de humanização torna a relação médico-paciente menos } \\
\text { sigilosa. }\end{array}$ \\
\hline
\end{tabular}




\begin{tabular}{|c|c|c|c|c|}
\hline Revista & Autores (ano) & Título & Objetivos & Conclusões \\
\hline $\begin{array}{l}\text { Revista Brasileira } \\
\text { de Educação } \\
\text { Médica }\end{array}$ & $\begin{array}{c}\text { GOMES LF, et al. } \\
(2017) .\end{array}$ & $\begin{array}{l}\text { Conhecimento de Libras pelos } \\
\text { Médicos do Distrito Federal e } \\
\text { Atendimento ao Paciente } \\
\text { Surdo. }\end{array}$ & $\begin{array}{l}\text { Avaliar o conhecimento de } \\
\text { LIBRAS por médicos do Distrito } \\
\text { Federal e sua percepção frente ao } \\
\text { atendimento de pacientes surdos. }\end{array}$ & $\begin{array}{l}\text { Destaca-se que LIBRAS é essencial antes ou durante a } \\
\text { formação médica e nos demais cursos da área de saúde. A } \\
\text { conscientização dos profissionais de saúde acerca do } \\
\text { atendimento integral do paciente surdo é um passo para } \\
\text { implementação eficaz do ensino de Libras de forma } \\
\text { especializada no ensino superior, resultando em maior } \\
\text { confiança e humanização na relação médico-paciente. }\end{array}$ \\
\hline $\begin{array}{l}\text { Revista Saúde e } \\
\text { Pesquisa }\end{array}$ & $\begin{array}{l}\text { LOPES RM, et al. } \\
(2017) .\end{array}$ & $\begin{array}{l}\text { Comunicação do surdo com } \\
\text { profissionais de saúde na } \\
\text { busca da integralidade. }\end{array}$ & $\begin{array}{l}\text { Problematizar e identificar a } \\
\text { concepção do surdo quanto à } \\
\text { comunicação com os profissionais } \\
\text { de saúde. }\end{array}$ & $\begin{array}{l}\text { Existem percalços para haver o atendimento humanizado aos } \\
\text { surdos devido à dificuldade de comunicação com os } \\
\text { profissionais de saúde. Conhecimento de Libras pela equipe de } \\
\text { saúde facilitaria a relação profissional-paciente. }\end{array}$ \\
\hline Revista Millenium & $\begin{array}{c}\text { FARIAS B e } \\
\text { CUNHA M (2017). }\end{array}$ & $\begin{array}{l}\text { Satisfação da pessoa surda } \\
\text { com a qualidade da } \\
\text { assistência em saúde. }\end{array}$ & $\begin{array}{l}\text { Avaliar a satisfação da pessoa } \\
\text { surda com a qualidade das ações } \\
\text { e serviços oferecidos nas } \\
\text { unidades de saúde públicas. }\end{array}$ & $\begin{array}{l}\text { A maioria dos participantes apontaram insatisfação com a } \\
\text { comunicação estabelecida com os profissionais de saúde. Não } \\
\text { conseguem informações suficientes para entender } \\
\text { adequadamente sobre o que é informado nas consultas. }\end{array}$ \\
\hline $\begin{array}{l}\text { Revista Eletrônica } \\
\text { de Enfermagem }\end{array}$ & $\begin{array}{l}\text { THOMAZ MM, et } \\
\text { al. (2019). }\end{array}$ & $\begin{array}{l}\text { Acessibilidade do adolescente } \\
\text { com } \\
\text { deficiência auditiva aos } \\
\text { serviços de saúde. }\end{array}$ & $\begin{array}{l}\text { Identificar a perspectiva do } \\
\text { cuidador familiar acerca das } \\
\text { experiências no acesso do } \\
\text { adolescente com deficiência } \\
\text { auditiva aos serviços de saúde. }\end{array}$ & $\begin{array}{l}\text { A falta de preparo e a insegurança dos profissionais dificultam } \\
\text { significativamente a qualidade e a humanização da assistência, } \\
\text { uma vez que a comunicação é a base para o entendimento } \\
\text { humano. }\end{array}$ \\
\hline $\begin{array}{l}\text { Revista Latino- } \\
\text { Americana de } \\
\text { Enfermagem }\end{array}$ & $\begin{array}{l}\text { SANTOS AS e } \\
\text { PORTES AJF } \\
\text { (2019). }\end{array}$ & $\begin{array}{l}\text { Perceptions of deaf subjects } \\
\text { about communication In } \\
\text { Primary Health Care. }\end{array}$ & $\begin{array}{l}\text { Analisar as percepções de } \\
\text { indivíduos surdos em relação ao } \\
\text { processo comunicacional com } \\
\text { profissionais de saúde da Atenção } \\
\text { Básica do Estado do Rio de } \\
\text { Janeiro. }\end{array}$ & $\begin{array}{l}\text { A comunicação com os profissionais foi facilitada quando os } \\
\text { surdos estavam com acompanhante ou quando utilizavam } \\
\text { mímicas e gestos, sendo a língua de sinais negligenciada, } \\
\text { apesar da legislação garantir aos surdos atendimento por } \\
\text { profissionais capacitados para o uso desta. }\end{array}$ \\
\hline
\end{tabular}


Com uma leitura profunda dos 11 artigos selecionados, pôde-se identificar 5 pontos principais, que foram categorizados: Comunicação, Mediadores, LIBRAS e Profissionais de Saúde, Direitos Legais e Comorbidades. Cada assunto será analisado e, se houver possibilidades, interconexões entre os artigos dentro da categoria específica. Comunicação foi a categoria que obteve mais frequência nos artigos analisados. Todos os artigos apresentaram em seus resultados comentários abordando as dificuldades encontradas tanto do lado do paciente, quanto para o lado do profissional de saúde, assim como avaliações da qualidade dos atendimentos, sendo que todas as críticas são baseadas nos resultados obtidos de cada artigo analisado. Outra categoria analisada também foram os mediadores. Observou-se que as experiências que possuem referente aos atendimentos médicos, também fornecem informações essenciais, que ajudam a entender o impacto do atendimento de um paciente surdo.

A categoria referente a Libras e os profissionais de saúde foi abordada com mais ênfase, especificamente, em três artigos dos treze que foram previamente selecionados. São pontuações pertinentes, visto que seus resulados apontam que há uma pequena minoria dos profissionais de saúde, que conseguem estabelecer contato utilizando linguagem de sinal durante consultas com não-ouvintes. Outra categoria abordada refere sobre os direitos dos surdos. Um dos artigos abordou o tema com mais ênfase, em relação aos demais. Importante denotar, que foi feito interconexões entre os pareceres encontrados nos resultados do devido artigo e as respectivas Leis brasileiras que asseguram o dever de prestar toda a assistência as necessidades da população surda.

A última categoria abordada, e uma das mais importante, refere-se aos estudos que apontam possíveis complicações de saúde acometidas na população surda. Um dos artigos traz um estudo comparando a população ouvinte com a população surda e as respectivas proporções de comorbidades que afligem cada uma delas. Importante deixar claro que os resultados estão consoantes com as informações observadas nas demais categorias do artigo. Segue abaixo, o desenvolvimento de cada uma das cinco categorias com suas respectivas análises críticas e possíveis interconexões textuais.

\section{Comunicação}

Importante denotar que os 11 artigos, sem exceção, analisados nesse estudo apresentaram a comunicação como deficitária na assistência à saúde. Em Farias B e Cunha M (2017) deixam claro em sua conclusão que surdos não entendem suficientemente o que é informado nas consultas. O estudo feito por Lopes RM, et al. (2017) constatou que a dificuldade do paciente está em informar ao profissional o motivo para a consulta, e um dos resultados obtidos no trabalho de Neves DB, et al. (2016) evidenciam que realmente os pacientes não conseguem expor todas as suas queixas, o que acaba deixando superficial o atendimento e o foco ficam centrados na resolução da sintomatologia.

Santos AS e Portes AJF (2019) ao declararam que $72 \%$ dos participantes relataram insegurança mesmo com a presença de um mediador durante o atendimento. Outro ponto do artigo de Lopes RM, et al. (2017) refere que a presença de um mediador, seja um familiar, seja um profissional intérprete retira a privacidade, o que pode induzir ao paciente não dizer tudo devido a vergonha, o que reforça o fato de que a comunicação prejudicada, aquém do que se espera. Em relação a compreensão do paciente durante a assistência, o artigo de Santos AS e Portes AJF (2019) denota que 70\% dos indivíduos não-ouvintes não entenderam o tratamento proposto pelo médico, e reforça que $82 \%$ desses indivíduos não compreenderam o diagnóstico. Esses resultados apontam que o objetivo de se ter um atendimento humanizado fica comprometido com a comunicação insuficiente. Essencial ratificar que para o sucesso terapêutico, o paciente necessita saber como proceder com manejo de medicamentos e cuidados necessários.

\section{Mediadores}

Uma perspectiva abordada no artigo de Thomaz MM, et al. (2019) se torna fundamental para melhor compreensão de um diferente ponto de vista. Trata-se do ponto de vista dos acompanhantes, cujo estudo analisado traz experiências desses participantes que atuam como mediadores dos atendimentos de saúde para os pacientes surdos. $O$ artigo traz a informação de que os pacientes surdos são assistidos por uma visão preconceituosa dos profissionais que os atendem. Atribuem esses pacientes como incapazes, debilitados e adoecidos. 
Em Souza MFNS, et al. (2017) apontam que as informações sobre diagnóstico e conduta terapêutica, são fornecidas aos familiares, que geralmente não dominam Libras o suficiente para explicar ao paciente o que foi decidido. Então fica claro que o paciente perde o protagonismo, cuja centralidade e atenção passa a ser exercida pelo acompanhante.

\section{LIBRAS e Profissionais de Saúde}

Em Cavagna VM, et al. (2017) apontam que 14 dos 15 participantes relatam que os profissionais de saúde não conhecem Libras. Infelizmente, há muitos profissionais de saúde que lembram apenas que LIBRAS é o modo com os surdos se comunicam. O trabalho que corrobora com essa ideia está em Nascimento GB, et al. (2015) ao relatar que $86 \%$ dos entrevistados surdos declararam que a atendimento foi com um profissional que desconhecia LIBRAS.

No artigo de Neves DB, et al. (2016) apresentam um dado que reforça essa informação ao salientar que há um pequeno número de profissionais aptos para se comunicarem em Língua de Sinais (LS), um percentual aproximado de $2 \%$. Então, fica claro a importância em estabelecer a melhor acessibilidade comunicativa entre ouvinte e não-ouvintes. Seguindo o raciocínio, no artigo de Gomes LF, et al. (2017) há um dado pertinente e que ratifica a frase anterior ao afirmar que $92 \%$ da amostra de participantes, que são médicos, já atenderam ao menos 1 paciente surdo e que $99 \%$ dos mesmos não sabiam LS.

Em Aragão JS, et al. (2017) apontam que a dificuldade da comunicação não verbal desvincula a interação médico-paciente. O que se pode extrair dessas informações é que o profissional de saúde necessita compreender melhor o paciente surdo para estabelecer a melhor relação comunicativa.

\section{Direitos Legais}

O artigo de Neves DB, et al. (2016) traz um dado denotando um de seus resultados ao afirmar que muitos serviços de saúde ficam inconcebíveis para os surdos pelo fato de não haver acessibilidade por meio da língua de sinais. O estudo acrescenta em seus resultados que há uma série de sentimentos que derivam da assistência médica, pois não enxergam suas necessidades. Inclui-se um outro dado também do respectivo estudo ao afirmar que esses pacientes tendem a ter com frequência as seguintes percepções: discriminação, isolados, desrespeitados. A questão que se deve reforçar é que a regulamentação do decreto 5.626, em vigor desde 2005, apresenta mais de 15 anos de existência, no entanto mesmo com todo esse tempo para ajustar os serviços prestados, ainda, majoritariamente, não há ofertas suficientes de serviços de apoio aos surdos para que a assistência seja suficiente.

\section{Comorbidades}

A pesquisa de Emond A, et al. (2015) apontou que apenas $42 \%$ da população surda tinha controle adequado para HAS em comparação com a população geral que tinha $62 \%$. A pressão arterial aumentada na população surda foi de $37 \%$ em comparação com a população geral que foi de $21 \%$. Outro dado menciona que $29 \%$ dos surdos relataram que não sabiam da hipertensão ao passo que na população geral a porcentagem foi de $6 \%$. A taxa de detecção de HAS na população geral foi de $58 \%$ para homens e $59 \%$ para mulheres, enquanto que para os surdos do sexo masculino a taxa de detecção foi de $44 \%$ e para participantes surdos do sexo feminino de $54 \%$. Foi pesquisado também envolveu a investigação sobre o desvio do peso dos entrevistados. Foi encontrado que em relação aos surdos $72 \%$ dos homens e $71 \%$ das mulheres estavam com sobrepeso, ao passo que na população geral do censo, considerando que ambos tenham a mesma relação de idade, a relação de sobrepeso encontrada foi de $65 \%$ para os homens e $58 \%$ para as mulheres.

O artigo de Emond A, et al. (2015) apontaram inclusive sobre Doenças Cardiovasculares (DVC), e foi verificado que a porcentagem da população geral com idade variando entre 55 a 84 anos, que faziam tratamento de Doença Cardíaca Isquêmica (DCl) e Acidente Vascular Cerebral (AVC) foi de $61 \%$, enquanto que a contraparte dos entrevistados, população surda, cuja variação de idade esteve entre 45 a 84 anos a porcentagem foi ainda menor, apresentando o valor de $45 \%$. Sobre os resultados envolvendo tabagismo e etilismo, foi verificando que na relação dos pacientes surdos e da população geral, ocorre menor uso de álcool e tabaco na população não-ouvinte. 


\section{CONSIDERAÇÕES FINAIS}

Observa-se que o atendimento à saúde do surdo fica aquém do esperado. Verifica-se nesse estudo que o atendimento é desafiador e muitas vezes frustrante para ambas as partes. A comunicação ineficiente é o principal fator que desestabiliza a relação médico-paciente. A análise dos dados sugere que os surdos tendem a possuir mais problemas de saúde em comparação com a população no geral. Não só as comorbidades crônicas podem desenvolver complicações precocemente, mas também as patologias menos graves podem resultar em problemas mais sérios, em vista da falta de informações adequadas ao paciente surdo. Recomenda-se estimular a educação profissional para adequar o atendimento do paciente não-ouvinte.

\section{REFERÊNCIAS}

1. ARAGÃO JM, et al. Access and communicaton os deaf adults: a voice silenced in health services. Revista de Pesquisa Cuidado é Fundamental Online, 2014; 6(1): 1-7.

2. BARNETT S, et al. Community participatory research with deaf sign language users to identify health inequities. Am $\mathrm{J}$ Public Health, 2011; 101(12): 2235-2238.

3. BRASIL. Lei no 10.436, de 24 de abril de 2002. Diário Oficial da União, 2002; 1:1 - 2. Disponível em: http:// www.planalto.gov.br/ccivil_03/leis/2002//10436.htm. Acesso em: 20 nov. 2020.

4. BRASIL. Decreto 5.626 de 22 dezembro de 2005. Diário Oficial da União, Brasília, DF, 23 de abril de 2005. Regulamenta a Lei 10.436 de 24 de abril de 2002. Dispõe sobre a Língua Brasileira de Sinais - Libras e o artigo 18 da Lei 10.098 de 19 de dezembro de 2000. 2005. Disponível em: http://www.planalto.gov.br/ccivil_03/_ato20042006/2005/decreto/d5626.htm. Acesso em: 20 nov. 2020.

5. CAVAGNA VM, et al. O paciente surdo e suas vivências no Sistema de saúde: uma interface coma enfermagem. Revista enfermagem atual, 2019;80(18); 33-39.

6. CHAVEIRO N, et al. Quality of life of deaf people who communicate in sign language: integrative review. Interface (Botucatu), 2014; 18(48): 101-114.

7. DUARTE SBR, et al. Aspectos históricos e socioculturais da população surda. História, Ciências, Saúde - Manguinhos, 2013; 20(4): 1713-1734.

8. EMOND A, et al. The current health of the signing Deaf community in the UK compared with the general population: a cross-sectional study. BMJ Open, 2015; 5(1): 1-7.

9. FARIAS B, CUNHA M. Satisfação da pessoa surda com a qualidade da assistência em saúde. Millenium, 2017; 2(4): 79-88.

10. FERNANDES S. Educação de surdos. 2 ed. Curitiba: Editora IBEPEX, 2011; 144p.

11. GOMES LF, et al. Conhecimento de Libras pelos médicos do Distrito Federal e atendimento ao paciente surdo. Revista Brasileira de Educação Médica, 2017; 41(3): 390-396.

12. INSTITUTO BRASILEIRO DE GEOGRAFIA E ESTATÍSTICA (IBGE). Pesquisa Nacional de Saúde 2013. 2013. Disponível em: https://biblioteca.ibge.gov.br/visualizacao/livros/liv94074.pdf. Acesso em 20 nov. 2020.

13. LOPES RM, et al. Comunicação do surdo com profissionais de saúde na busca da integralidade. Saúde e Pesquisa, 2017.

14. MELO CS, et al. Limites e possibilidades parao cuidado em saúde à pessoa surda: perspectivas da equipe multiprofissional. Revista eletrônica Acervo Saúde, 2021; 13(7): 1-8.

15. NASCIMENTO GB, et al. Estratégias de comunicação como dispositivo para o atendimento humanizado em saúde da pessoa surda. Revista Saúde, 2015; 41(2): 241-250.

16. NEVES DB, et al. Atendimento aos surdos nos serviços de saúde: acessibilidade e obstáculos. Infarma - Ciências Farmacêuticas, 2016; 28(3): 157-165.

17. NOBREGA JR, et al. Identidade surda e intervenções em saúde na perspectiva de uma comunidade usuária de língua de sinais. Ciência Saúde Coletiva, 2012; 17(3): 671-679.

18. SACKS O. Vendo vozes: uma viagem ao mundo dos surdos. São Paulo, Companhia das Letras, 2010; $216 \mathrm{p}$.

19. SANTOS AS, et al. Perceptions of deaf subjects about communication in Primary Health Care. Revista Latino Americana de Enfermagem, 2019; 27: 1-9.

20. SANTOS AS, PORTES AJF. Perceptions of deaf subjects about communication in Primary Health Care. Revista Latino Americana de Enfermagem, 2019; 27: 1-9.

21. SOUZA MFNS, et al. Main difficulties and obstacles faced by the deaf Community in health access: na integrative literature review. Revista CEFAC, 2017; 19(3): 395-405.

22. STROBEL K. História e ducação de surdos. Florianópolis: UFSC, 2009; 49p.

23. STROBEL K. As imagens do outro sobre a cultura surda. 4 ed. Florianópolis: UFSC, $2016 ; 146 \mathrm{p}$.

24. THOMAS MM, et al. Acessibilidade do adolescente com deficiências auditiva aos serviços de saúde. Rev. Eletr. Enferm, 2019; 21: 1-7.

25. TRECOSSI MO, ORTIGARA EPF. Importância e eficácia das consultas de enfermagem ao paciente surdo. Revista de Enfermagem, 2013; 9(9): 60-69.

26. WITKOSKI SA. Introdução à Libras: língua, história e cultura. Curitiba: Editora UTFPR, 2015; 198 p. 